\title{
Editorial
}

\section{Places and perceptions in contemporary city}

\author{
URBAN DESIGN International (2013) 18, 111-113. doi:10.1057/udi.2013.1
}

The senses contribute to a primary knowledge of the world. According with Lynch (1960, p. 3), 'Structuring and identifying the environment is a vital ability among all mobile animals. Many kinds of cues are used: the visual sensations of colour, shape, motion or polarization of light, as well as other senses such as smell, sound, touch, kinaesthesia, sense of gravity, and perhaps of electric or magnetic fields'.

The sensory stimuli are generally perceived as a whole: people may experience them individually in specific actions or by paying attention to a particular perception. 'The individual dimension can only be separated out by deliberate actions (closing one's eyes, blocking one's nose or ears) or by selective attention. While vision is the dominant sense, the urban environment is not perceived visually' (Carmona et al, 2010).

Usually, perceptions are the expression of local, religious and political identities, but there may be other cultural motivations that, by imposing new modes of behaviour and tastes, have an influence on the overall perceptions of the environment we live in. In spite of a general tendency in the contemporary city for perceptions to be blunted, it is still possible to identify their origins (Sepe, 2013).

\section{Visual Perception}

Whether or not a place is recognisable is largely a matter of visual images: colours, architectural typology, natural elements. As Porteous (1996, p. 31) observes, 'Psychologists, urban designers, landscape architects and advertisers all stress vision as the chief mode of knowing about the world. So much so, indeed, that when we use the term perception we almost always mean visual perception'. But vision is not enough to form a comprehensive idea of a place. Our eyes do not allow us to see in the back of the heads and our arc of vision is limited to what is before us. This determines a sort of 'psychological distance' between whoever observes and what is observed (Porteous, p. 31). Furthermore, 'our sense and our locomotor apparatus paint a clear picture of an extremely alert pedestrian who looks ahead and down, but has a limited field of upward vision. (...) This whole account of the horizontal sensory apparatus is the key to how we experience space, for example, how much of buildings pedestrians experience when walking along streets. Naturally that also impacts on the experience of low-rise and tall buildings in cities. In general, the upper floors of tall buildings can only be seen at a distance and never close up in the cityscape' (Gehl, 2010, p. 41).

The most apparent elements of vision nowadays are those of advertising; the image of the city and its elements has changed, and publicity has become the discriminating factor, bringing about changes in behaviour (routes taken, objects purchased and so on), so that places have been turned into one long commercial. Another important element of great visual suggestion is represented by some contemporary architecture, whose shape is created independently by the context and whose main ob jective is aesthetic. These kinds of buildings have the main function of capturing the attention of observers. The risk is that the cities are increasingly characterized by these symbols of globalisation with a resulting homologation of places.

The grey colour of the streets also characterises many places in the contemporary city: 'Grey is the canvas on top of which the city plays itself out. The buildings do not feel independent. Asphalt's homogenizing feel shrouds the city at ground level in a veil interspersed by signage and yellow and red traffic lines' (Landry, 2006, p. 73). And within the streets, the sheer volume of means of transport and in particular cars affects the vision of the city, often obscuring the overall vistas.

\section{Sound Perception}

Each town has its own sound. Porteous (1996, p. 33) observes that, unlike the space created by visual perception which is 'sectoral', the acoustic space is 'all surrounding': 'It has no obvious boundaries, and, in contrast with vision, tends to emphasise space itself rather than objects in space. Sounds, compared with things seen, are more transitory, more fluid, more unfocused, 
more lacking in context, less precise in terms of orientation and localisation, and less capturable. Audition is a fairly passive sense; one cannot close one's earlids. Sound, therefore, is ubiquitous; there is no end to traffic roar, building and machine hum, the rustling of leaves. Sudden silence can be extremely disconcerting'.

The materials used for streets, urban furniture and buildings determine the new sound of the contemporary city: 'Concrete, glass and steel create a "canyon effect" that loudens the growls and honks of traffic, sirens and exhaust from big buildings. The sound artist and urban observer Hildegard Westerkamp sums up parallel developments in modern architecture, as exemplified by the Bauhaus movement, and sound. She points out that the new international architecture that is homogenizing our visual urban environment is also homogenizing our soundscape' (Landry, 2006, p. 52).

In general, one can observe an overall homogenisation of the urban soundscape, making it more and more difficult to recognise a specific sound quality from city to city. This is due in part to the increasing noise pollution produced by transport, traffic, music played at a high volume to attract clientele into shops, and also to new patterns of cultural behaviour that have gradually modified the prevailing soundscape. And, as pointed out by Landry (p. 52), also 'Air conditioning provides a constant background whirr and computers an electrical hum. So the noise of global transactions is a broadband hum. (...) Even in the suburbs we have lost the art of silence; gardening equipment grinds, grates and whirrs. Overwhelming everything is the big petrochemical roar of the car, but we do not notice it anymore'.

\section{Smell Perception}

The sense of smell provokes emotive sensations, and, unlike sight, directly involves thought and cognition. Indeed, the sense of smell has an almost subconscious relationship to the emotions: a smell can recall a situation, place or city better than an image. It is of great importance for the human psyche and behaviour, and has had a considerable influence on the construction and evolution of the city. The cultural diversity of smells becomes an environmental component of the difference between places.

Each place features a set of smells that varies as the seasons and time of day change, although not everybody is able to identify this characteristic: «cities with the smell of curry, or on the sea with a mixture of brine and rust, cities with a stale, mouldy smell, and others with the acrid smell of burnt out cables» (Barbara and Perliss, 2006, p. 125).

According to Pergola (1997), the current shift in the perception of smells is due to the difficulty of disposing of rubbish (which is increasing as the population grows), atmospheric pollution caused by car exhaust fumes, and the lack of any official policy concerning smells. Another element that is contributing to the homologation of smells is the fast-food chain: 'The fast-food chains have a smell of their own. McDonald's, KFC, Wendy's, Subway, Burger King. They mush into one. They are almost sweet, crusty, a slight smell of cardboard, dry. Grease and ketchup liberates and heightens the papery cardboard smell from which you eat the chips and chicken nuggets'.

\section{Taste Perception}

The sense of taste represents a contact linked with the survival of human beings (one cannot live without eating), but also with pleasure, or disgust, and like the sense of smell it is closely bound up with the subconscious. Food is connected with local traditions and also habits, and is able to evoke places, situations and people. Current market trends have fostered two different attitudes: on the one hand, the proliferation of supermarkets and hypermarkets, fast-food takeaways and so on, selling standard products, and on the other the creation or conversion of delicatessens, patisseries and small restaurants featuring choice products and typical local fare.

In terms of the relationship with the city, this trend has had a considerable influence, introducing changes that, as we have seen in the case of the sense of smell, have involved other perceptive aspects. In addition to the different tastes, in the street one is struck by glaring advertisements for businesses, you hear background noise and various types of music played at full volume inside the shops, you are assailed by odours from the kitchens and you come into contact with food containers increasingly made of plastic, cardboard or aluminium.

Furthermore, Barbara (2000), referring to a story by Italo Calvino (1995), attempts to place food in relation to architecture, drawing various parallels, for example, between the Mediterranean diet and 
Mediterranean architecture. '... the true journey, involving the interiorisation of a setting which is different from the one we are accustomed to, implies a total change in what we eat, as if it was a matter of ingesting the country we are visiting, its fauna and flora but also its culture (not only the different habits in cooking and seasoning but also the use of different instruments for grinding the flour or stirring the dough), taking them in as it were through the lips and the gullet. This is the only way to travel in this day and age, when everything you can set eyes on is there in front of you on television, without you having to move from your armchair'.

\section{Tactile Perception}

Unlike the other senses that have a demonstrable link with the spatial dimension of the city, tactile sensations involve perception in close-up, requiring you to recognise the material quality of objects. We touch the setting around us in various ways, and the perception deriving from the use of one material rather than another is able to bring about a significant change in the overall perception of a place. The paving beneath our feet, the handrail we use when going up or down steps, the handle on a door, the seat we use to pause and admire a monument or wait for a bus have all gone through many variations with the passage of time. As Porteous (p. 38) notes: 'Textural experience, just as with sound and smell, is thereby eliminated or severely reduced. An increased use of textured sidewalks (gravel, tile, metal, glass, brick, wood) and Portuguese-style mosaics would greatly enhance the sensuous pleasure of city walking'.

'If paving using flagstones', as Pergola (1997) remarks, 'was once beguiling, this was connected above all with the fact that getting somewhere on foot involved a whole amount of information and sensations concerning time and route that are obviously lost in a mechanised transfer. (...) The perception of levelling out, of removing all irregularities, is commensurate with the need for speed but also for non-permanence in a specific place and with a neutralised environment'. The industrial production of objects in everyday use has begun to show a great interest in the tactile message of electronic gadgets and the materials available for paving, walls, furniture and so on. In the same way, there is a diversification in the production of handles, concerning form and materials, with particular attention to the tactile properties of the material used: "when it comes down to it, the handle, however small, has a key role to play in the context of a door, wall or overall architecture, bestowing a touch of vitality: a handle immediately tells us whether a door is being used or not: if it was used recently it may even still be warm to the touch. But what can we expect of an automatic door in a supermarket or airport, which is not even touched?».

The recognition of a place is strongly determined by the sense stimuli, and one of the main components of place identity is our perceptions: 'The identity of places is multisensory, but in some cases one or more sense perceptions may be dominant. Sensory interaction is vital; people who hear more, for example, also see more (Southworth, 1969). Kinaesthesia (motion by foot or vehicle) is the sense which most readily helps integrate the other senses over time' (Porteous, p. 41).

The pleasure related to experiencing a place through the senses is hence considerable. Adequate attention should be paid to sensory quality, and specific policies designed to safeguard or enhance the perceptions as a whole have to be carried out in design and planning processes. Otherwise, as Porteous (1996, p. 41) has warned, 'urbanites will continue to regard cities as sensory blackspots and seek sensory pleasure chiefly indoors, in private gardens, public parks, and nonurban rural and wilderness areas'.

\section{References}

Barbara, A. (2000) Storie di architettura attraverso i sensi. Milan, Italy: Bruno Mondadori.

Barbara, A. and Perliss, A. (2006) Invisible Architecture. Milan, Italy: Skira.

Calvino, I. (1995) Sotto il sole giaguaro. Milan: Mondadori.

Carmona, M., Heath, T., Oc, T. and Tiesdell, S. (2010) Public Places-Urban Spaces. Oxford: Architectural Press.

Gehl, J. (2010) Cities For People. Washington DC: Island Press. Landry, C. (2006) The Art of City Making. London: Earthscan.

Lynch, K. (1960) The Image of the City. Cambridge MA: MIT Press.

Pergola, C. (1997) La città dei sensi. Firenze, Italy: Alinea.

Porteous, J.D. (1996) Environmental Aesthetics: Ideas, Politics and Planning. London: Routledge.

Sepe, M. (2013) Planning and Place in the City. Mapping Place Identity. London-New York: Routledge.

Southworth, M. (1969) The sonic environment of cities. Environment and Behavior 1(1): 49-70.

Marichela Sepe

IRAT - National Research Council, DARC - University of Naples Federico II, Italy. 